\title{
Analisis Efektivitas Dan Efisiensi Sistem Informasi Akuntansi Pada Aplikasi DANA Untuk Mengatur Keuangan Masyarakat
}

\author{
Mardiana $^{1}$, Salsabillah Devia Khansa ${ }^{2}$, Risky Wulandari ${ }^{3}$ \\ ${ }^{1}$ Program Studi Akuntansi Universitas Raharja, ${ }^{2,3}$ Program Studi Sistem Informasi Universitas \\ Raharja \\ E-mail : *11 mardiana@ raharja.info, ${ }^{2}$ salsabillah.devia@ raharja.info, ${ }^{3}$ risky@ raharja.info
}

\begin{abstract}
Abstrak
Di era digital saat ini, banyak masyarakat yang sudah menerapkan sistem digital untuk mendukung aktivitas sehari-hari. Salah satunya adalah untuk mengatur keuangan. Aplikasi DANA merupakan salah satu dari banyak aplikasi pengelola keuangan yang ada di Indonesia. Pada aplikasi tersebut, pengguna dapat mengatur keuangan seperti pemasukan, pengeluaran, belanja, dan lainnya, juga tersedia data serta informasi keuangan pengguna. Namun, apakah aplikasi tersebut sudah efektif dan efisien untuk mengatur keuangan? Pada penelitian ini akan dilakukan survei menggunakan kuesioner dengan 102 responden yang merupakan pengguna aplikasi DANA. Hasil dari penelitian ini menunjukkan bahwa mayoritas responden merasa aplikasi DANA sudah efektif untuk mengatur/mengelola keuangan serta kualitas sistem informasi dan informasi akuntansi yang disediakan cukup baik, dan juga efisien dalam penggunaan aplikasinya. Serta mayoritas responden berpendapat bahwa aplikasi DANA sudah cukup dikenal dan juga cukup bermanfaat untuk mengatur keuangan.
\end{abstract}

Kata Kunci : Sistem informasi akuntansi, sistem informasi, pengelolaan keuangan, keuangan digital.

\section{Abstract}

In today's digital era, many people have implemented digital systems to support their daily activities. One of them is to manage finances. The DANA application is one of the many financial management applications in Indonesia. In this application, users can manage finances such as income, expenses, shopping, and others, as well as user financial data and information. However, is the application effective and efficient for managing finances? In this study, a survey will be conducted using a questionnaire with 102 respondents who are users of the DANA application. The results of this study indicate that the majority of respondents feel that the DANA application has been effective in managing finances and the quality of the information system and accounting information provided is quite good, and also efficient in using the application. And the majority of respondents believe that the DANA application is well known and also quite useful for managing finances.

Keywords: Accounting information systems, information systems, financial management, digital finance.

\section{Pendahuluan}

Perkembangan ilmu pengetahuan dan teknologi telah membawa masyarakat Indonesia ke arah hidup yang bersifat modern. Dengan perkembangan teknologi yang semakin pesat dan cepat ini, hampir tiap individu dapat menggunakan teknologi dengan baik sesuai dengan 
kebutuhannya. Perkembangan teknologi dan informasi memberikan kemudahan kepada masyarakat dan memberikan masukan untuk dapat memahami perkembangan teknologi informasi agar masyarakat dapat berkomunikasi dan bersosialisasi dengan siapapun dan dimanapun keberadaannya dengan baik dan benar ${ }^{[1]}$.

Teknologi tidak hanya dipakai oleh masyarakat untuk bersosialisasi saja, namun juga dipakai untuk mendukung aktivitas sehari-hari misalnya untuk mengatur keuangan. Saat ini sudah banyak jenis platform yang mengatur keuangan dengan menerapkan sistem informasi akuntansi yang memudahkan masyarakat dalam mengatur keuangan seperti pengeluaran dan pemasukan.

Perkembangan teknologi informasi berdampak signifikan terhadap Sistem Informasi Akuntansi (SIA), dampak yang dirasakan adalah dalam hal penerapan dari proses manual hingga saat ini berubah ke sistem terkomputerisasi dengan hardware dan software yang lebih maju serta sumber daya manusia yang lebih handal ${ }^{[2]}$. Sistem Informasi Akuntansi (SIA) dirancang sedemikian rupa oleh suatu organisasi atau lembaga sehingga dapat memenuhi fungsinya yaitu menghasilkan informasi akuntansi yang relevan, handal, dapat dibandingkan, dan dapat dipahami, dengan sistem informasi akuntansi yang layak dapat dihasilkan suatu laporan yang mampu memberikan berbagai informasi yang berguna bagi pihak-pihak pengambil keputusan ${ }^{[3]}$ karena informasi akuntansi yang berkualitas merupakan harapan yang diinginkan pengguna agar dapat dijadikan dasar dalam proses pengambilan keputusan ${ }^{[4]}$.

Tren penggunaan digital payment di Indonesia semakin meningkat dari tahun ke tahun. Layanan digital payment ini telah dirasakan manfaatnya untuk semua kalangan ${ }^{[5]}$. Saat ini sudah banyak sekali perusahaan yang membuat suatu platform dengan fasilitas untuk mengatur keuangan secara digital, salah satunya PT Espay Debit Indonesia Koe yang merupakan sebuah perusahaan yang menghadirkan produk e-money yaitu DANA atau sering disebut Dompet Digital, salah satu alternatif produk dompet digital di tengah-tengah masyarakat Indonesia ${ }^{[6]}$. Pada aplikasi DANA, masyarakat dapat melakukan transaksi pembelian dan pembayaran secara online melalui smartphone masing-masing. Namun, apakah penggunaan aplikasi DANA dinilai efektif dan efisien untuk bertransaksi? Apakah aplikasi DANA dapat menghasilkan data dan informasi akuntansi yang bermanfaat dan mudah dipahami oleh penggunanya?

Berdasarkan pemaparan diatas, peneliti tertarik untuk mengkaji lebih dalam lagi mengenai penerapan sistem informasi akuntansi pada aplikasi DANA, dan juga efektivitas dan efisiensi penggunaan aplikasi DANA oleh masyarakat.

\section{Metode Penelitian}

Untuk pengumpulan data efisiensi dan efektivitas pada penggunaan aplikasi DANA, peneliti menggunakan pendekatan analisis kuantitatif dengan cara survei. Sasaran survei yang peneliti targetkan adalah pengguna aplikasi DANA pada masyarakat. Media yang digunakan pada survei ini adalah berupa kuesioner online pada Google Form dan Google Spreadsheet untuk mengolah data survei yang masuk.

Jenis data pada penelitian ini adalah data kuantitatif berupa jumlah dan persentase jawaban dari setiap pertanyaan yang diisi oleh responden. Pertanyaan pada kuesioner ini mencakup tiga bagian, yaitu mengenai kualitas sistem informasi, kualitas informasi akuntansi, dan tanggapan persepsi responden terhadap aplikasi DANA.

Selain menggunakan metode survei, peneliti juga menggunakan metode pengumpulan data berupa studi pustaka melalui buku, artikel, jurnal, dan media lainnya untuk menunjang penelitian. Penelitian yang dilakukan menggunakan bahan/materi, yaitu peneliti melakukan penelitian berupa pengumpulan data dengan cara mempelajari dan membaca dokumen-dokumen dari perusahaan yang terkait, dari buku-buku yang berhubungan dengan data yang diperlukan, serta dari internet terutama mengenai berbagai penelitian terkait ${ }^{[7]}$. 


\section{Hasil dan Pembahasan}

Penggunaan sistem informasi akuntansi (SIA) dapat meningkatkan kualitas informasi, mengurangi biaya informasi, meningkatkan ketepatan dalam pengambilan keputusan, dan meningkatkan pembagian pengetahuan (knowledge sharing). Output dari sistem informasi akuntansi adalah informasi-informasi yang akan berguna dalam mengukur kinerja keuangan dan menghasilkan laporan keuangan yang akurat ${ }^{[8]}$, oleh karena itu peran sistem informasi akuntansi sangat penting untuk menentukan efisiensi dan efektivitas pada aplikasi DANA.

DANA atau dompet digital Indonesia adalah sebuah layanan keuangan digital application based yang mana aplikasinya telah tersedia untuk platform android melalui Google Play Store maupun platform iOS melalui App Store. Aplikasi ini memungkinkan pengguna untuk melakukan banyak hal seperti melakukan pembelian pulsa, pembayaran belanja, transfer uang, dan lainnya ${ }^{[9]}$. Aplikasi ini menerapkan sebuah sistem informasi untuk meningkatkan pengalaman pengguna saat menggunakan aplikasi seperti kenyamanan tampilan aplikasi, sistem yang ramping, efisien, dan lain-lain.

Salah satu tolak ukur kesuksesan penerapan sebuah sistem informasi adalah kepuasan pengguna ${ }^{[10]}$. Oleh karena itu, peneliti melakukan survey untuk mengetahui bagaimana tanggapan responden yang merupakan pengguna aplikasi DANA. Peneliti melakukan survei menggunakan Google Form dimulai sejak tanggal 2 Agustus 2021 sampai dengan 14 Agustus 2021. Responden yang diperoleh dalam penelitian ini sebanyak 102 orang pengguna aplikasi DANA. Tujuan dari survei ini adalah untuk mengukur efisiensi dan efektivitas aplikasi DANA berdasarkan kualitas sistem informasi dan pendapat responden terhadap aplikasi tersebut.

\subsection{Profil Responden}

Tabel 1 Profil Responden

\begin{tabular}{|l|c|c|}
\hline \multicolumn{1}{c}{ Karakteristik } & Jumlah & Presentase \\
\hline Laki-laki & 45 & $44 \%$ \\
\hline Perempuan & 57 & $56 \%$ \\
\hline
\end{tabular}

Sumber : Data diolah berdasarkan hasil survei

Berdasarkan data tabel 1 dapat dilihat dari 102 responden berdasarkan jenis kelamin, diperoleh sebanyak $44 \%$ laki-laki dan $56 \%$ perempuan dengan jumlah keseluruhan 45 laki-laki dan 57 perempuan. Dari data tersebut dapat disimpulkan bahwa responden pengguna aplikasi DANA merupakan mayoritas berjenis kelamin perempuan.

\subsection{Perhitungan Hasil Survei Efisiensi dan Efektivitas SIA pada Aplikasi DANA}

Peneliti menyediakan sebanyak 10 pertanyaan kepada responden dan pertanyaanpertanyaan tersebut dibagi menjadi 3 bagian. Bagian pertama merupakan penilaian mengenai kualitas sistem informasi, kedua mengenai kualitas informasi akuntansi, dan ketiga bagian persepsi responden terhadap aplikasi DANA.

\subsubsection{Perhitungan Bagian Kualitas Sistem Informasi}

*Keterangan :

STS : Sangat Tidak Setuju

TS : : Tidak Setuju

S : : Setuju

SS : Sangat Setuju

Tabel 2 Perhitungan Bagian Kualitas Sistem Informasi

\begin{tabular}{|l|c|c|c|c|}
\hline \multirow{2}{*}{ Pertanyaan } & \multicolumn{4}{c}{ Skor (\%) } \\
\cline { 2 - 5 } & STS $^{*}$ & TS $^{*}$ & $\mathrm{~S}^{*}$ & SS $^{*}$ \\
\hline $\begin{array}{l}\text { Tampilan aplikasi DANA menarik } \\
\text { dan mudah dipahami. }\end{array}$ & $3 \%$ & $3 \%$ & $55 \%$ & $39 \%$ \\
\hline
\end{tabular}




\begin{tabular}{|c|c|c|c|c|}
\hline $\begin{array}{lcr}\text { Aplikasi } & \text { DANA efektif } & \text { untuk } \\
\text { mengatur } & \text { pengeluaran } & \text { dan } \\
\text { pemasukan anda } & \end{array}$ & $1 \%$ & $14 \%$ & $64 \%$ & $22 \%$ \\
\hline $\begin{array}{l}\text { Aplikasi DANA sangat tidak efisien } \\
\text { untuk mengatur keuangan karena } \\
\text { memakan banyak biaya dan waktu } \\
\text { pada saat pengoprasiannya }\end{array}$ & $25 \%$ & $47 \%$ & $24 \%$ & $5 \%$ \\
\hline $\begin{array}{l}\text { Menggunakan aplikasi dana dirasa } \\
\text { lebih efektif dan efisien dalam } \\
\text { bertransaksi }\end{array}$ & $2 \%$ & $6 \%$ & $62 \%$ & $30 \%$ \\
\hline
\end{tabular}

Sumber : Data diolah berdasarkan hasil survei

Analisis responden pada table 2 ini bertujuan untuk menganalisis bagaimana kualitas sistem informasi pada aplikasi DANA menurut 102 responden yang didapat. Untuk penilaian kualitas sistem informasi, peneliti mengambil penilaian berdasarkan tampilan aplikasi serta efisiensi dan efektivitas terhadap user experience (UX) dan proses fungsional pada aplikasi DANA. Pertama untuk penilaian tampilan aplikasi DANA, 94\% responden menyatakan bahwa aplikasi DANA menarik dan mudah dipahami. Kemudian untuk penilaian user experience, $72 \%$ responden merasa bahwa aplikasi DANA cukup efisien dalam pengoprasiannya karena tidak memakan banyak waktu dan biaya. Terakhir untuk penilaian proses fungsional, $86 \%$ responden menyatakan bahwa aplikasi DANA efektif dan efisien untuk mengatur pengeluaran dan pemasukan, dan juga $92 \%$ responden menyatakan bahwa dengan menggunakan aplikasi DANA dirasa lebih efektif dan efisien dalam bertransaksi.

\subsubsection{Perhitungan Bagian Kualitas Informasi Akuntansi}

* Keterangan :

$\begin{array}{ll}\text { STS } & \text { : Sangat Tidak Setuju } \\ \text { TS } & \text { : Tidak Setuju } \\ \text { S } & \text { : Setuju } \\ \text { SS } & \text { : Sangat Setuju }\end{array}$

Tabel 3 Perhitungan Bagian Kualitas Informasi Akuntansi

\begin{tabular}{|l|c|c|c|c|}
\hline \multirow{2}{*}{ Pertanyaan } & \multicolumn{3}{c}{ Skor (\%) } \\
\cline { 2 - 5 } & STS $^{*}$ & $\mathrm{TS}^{*}$ & \multicolumn{1}{c}{$\mathrm{S}^{*}$} & $\mathrm{SS}^{*}$ \\
\hline $\begin{array}{l}\text { Pada aplikasi DANA terdapat } \\
\text { informasi yang anda butukan (seperti } \\
\text { laporan keuangan, jumlah saldo, dan } \\
\text { lainnya) }\end{array}$ & $3 \%$ & $6 \%$ & $52 \%$ & $39 \%$ \\
\hline $\begin{array}{l}\text { Anda sering menggunakan data dan } \\
\text { informasi keuangan anda yang tersedia } \\
\text { pada aplikasi DANA }\end{array}$ & $2 \%$ & $15 \%$ & $52 \%$ & $31 \%$ \\
$\begin{array}{l}\text { Anda menggunakan aplikasi DANA } \\
\text { karena aplikasi dapat menyediakan } \\
\text { semua data dan informasi yang anda } \\
\text { butuhkan untuk mengatur keuangan } \\
\text { anda }\end{array}$ & $4 \%$ & $15 \%$ & $44 \%$ & $37 \%$ \\
\hline
\end{tabular}

Sumber : Data diolah berdasarkan hasil survei

Analisis responden pada table 3 ini bertujuan untuk menganalisis bagaimana kualitas informasi akuntansi pada aplikasi DANA menurut 102 responden yang didapat. Untuk penilaian kualitas informasi akuntansi, peneliti mengambil penilaian berdasarkan 
ketersediaan data dan informasi keuangan serta frekuensi penggunaan data dan informasi keuangan pada aplikasi DANA. Pertama untuk penilaian ketersediaan data dan informasi keuangan, $86 \%$ responden menyatakan bahwa aplikasi DANA sudah menyediakan data dan informasi keuangan yang responden butuhkan. Dan untuk penilaian frekuensi penggunaan data dan informasi keuangan, $83 \%$ responden sering menggunakan data dan informasi keuangan yang tersedia aplikasi DANA.

\subsubsection{Perhitungan Bagian Persepsi Responden Terhadap Aplikasi DANA}

* Keterangan :

STS : Sangat Tidak Setuju

TS : Tidak Setuju

S : Setuju

SS : Sangat Setuju

Tabel 4 Perhitungan Bagian Persepsi Responden Terhadap Aplikasi DANA

\begin{tabular}{|c|c|c|c|c|}
\hline \multirow{2}{*}{ Pertanyaan } & \multicolumn{4}{|c|}{ Skor (\%) } \\
\hline & STS $^{*}$ & $\mathrm{TS}^{*}$ & $\mathrm{~S}^{*}$ & $\mathrm{SS}^{*}$ \\
\hline $\begin{array}{l}\text { Anda sudah lama mengenal aplikasi } \\
\text { DANA }\end{array}$ & $3 \%$ & $10 \%$ & $56 \%$ & $31 \%$ \\
\hline $\begin{array}{l}\text { Aplikasi DANA sangat membantu } \\
\text { anda dalam mengatur keuangan }\end{array}$ & $5 \%$ & $7 \%$ & $62 \%$ & $26 \%$ \\
\hline $\begin{array}{l}\text { Aplikasi DANA dapat mempengaruhi } \\
\text { jumlah pengeluaran anda }\end{array}$ & $10 \%$ & $16 \%$ & $64 \%$ & $11 \%$ \\
\hline
\end{tabular}

Sumber : Data diolah berdasarkan hasil survei

Analisis responden pada table 4 ini bertujuan untuk menganalisis persepsi responden terhadap aplikasi DANA menurut 102 responden yang didapat. Untuk pengamatan persepsi responden, peneliti menganalisis berdasarkan kapan responden mengenal aplikasi DANA, apakah aplikasi Membantu responden untuk mengatur keuangan, dan apakah aplikasi DANA dapat mempengaruhi jumlah pengeluaran responden. Pertama untuk pengamatan kapan responden mengenal aplikasi DANA, sebanyak $87 \%$ responden menyatakan mereka sudah lama mengenal aplikasi DANA, artinya aplikasi DANA ini bisa dikatakan cukup populer di masyarakat. Dan 13\% responden berpendapat bahwa mereka baru mengenal bahkan tidak tahu aplikasi DANA. Kemudian untuk pengamatan apakah responden merasa terbantu untuk mengatur keuangan dengan menggunakan aplikasi DANA, 88\% responden merasa terbantu dalam mengatur keuangan dengan menggunakan aplikasi DANA, dan $12 \%$ tidak merasa terbantu. Terakhir adalah pengamatan mengenai pengaruh aplikasi DANA terhadap pengeluaran responden. Sebanyak $75 \%$ berpendapat bahwa aplikasi DANA cukup berpengaruh terhadap pengeluaran keuangan, dan 26\% merasa aplikasi DANA tidak mempengaruhi pengeluaran responden.

\section{Kesimpulan}

Penelitian ini bertujuan untuk mengetahui penerapan sistem informasi akuntansi pada aplikasi DANA, dan juga efektivitas dan efisiensi penggunaan aplikasi DANA oleh masyarakat berdasarkan data yang diambil menggunakan metode survei kuesioner. Dari 102 responden dimana $44 \%$ laki-laki dan 56\% perempuan dapat disimpulkan bahwa :

1. $86 \%$ responden berpendapat bahwa kualitas sistem informasi pada aplikasi DANA sudah baik juga efektif dan efisien untuk digunakan. Sedangkan $14 \%$ berpendapat bahwa kualitas sistem informasi pada aplikasi DANA kurang efektif dan efisien. 
2. $85 \%$ responden berpendapat bahwa kualitas informasi akuntansi pada aplikasi DANA sudah cukup baik yang artinya pada aplikasi tersebut sudah menyediakan data dan informasi keuangan yang berguna bagi penggunanya. Sedangkan $15 \%$ responden berpendapat kualitas informasi akuntansi pada aplikasi DANA masih kurang baik dan pengguna jarang menggunakan data dan informasi akuntansi pada aplikasi tersebut.

3. Kemudian untuk persepsi responden terhadap aplikasi DANA didapat bahwa $83 \%$ responden sudah mengenal cukup baik aplikasi DANA dengan $87 \%$ responden menyatakan sudah lama mengenal aplikasi DANA dan $81,5 \%$ responden berpendapat bahwa aplikasi DANA cukup membantu untuk mengatur keuangan. Sedangkan 17\% lainnya menyatakan bahwa mereka belum terlalu mengenal aplikasi DANA, dan juga berpendapat bahwa aplikasi tersebut kurang membantu dan berpengaruh untuk mengatur keuangan.

\section{Daftar Pustaka}

[1] Pardani, Kadek Kusuma., Damayanthi, I Gst Ayu Eka. "Pengaruh Pemanfaatan Teknologi, Partisipasi Pemakai, Manajemen Puncak Dan Kemampuan Pemakai Terhadap Efektivitas Sistem Informasi Akuntansi”. E-Jurnal Akuntansi, [S.1.], v. 19, n. 3, p. 2234-2261, june 2017. ISSN 2302-8556.

[2] Jayantara, I. K., \& Dharmadiaksa, I. B. (Desember (2016). "Pengaruh Kemampuan Teknik Pemakai Dan Efektivitas Sistem Informasi Akuntansi (Sia)Terhadap Kinerja Individual”. E-Jurnal Akuntansi Universitas Udayana, Vol.17.3, pp. 2145-2170.

[3] Indana Zulfah, Sri Wahyuni dan Arina Nurfaza. "Pengaruh Sistem Informasi Akuntansi Terhadap Kualitas Laporan Keuangan Pada SKPD Kabupaten Aceh Utara”. Jurnal Akuntansi dan Pembangunan. Vol. 3, no. 2, p. 46-57. November 2017.

[4] Darma, J., \& Sagala, G. (2020). "Pengaruh Kualitas Sistem Informasi Akuntansi Terhadap Kualitas Informasi Akuntansi”. Jurnal Ilmiah MEA (Manajemen, Ekonomi, \& Akuntansi), 4(1), 227-237. https://doi.org/10.31955/mea.vol4.iss1.pp227-237.

[5] Iradianty, A. (Oktober 2020 ). "Indonesian Student Perception in Digital Payment". Jurnal Manajemen Bisnis, Volume 17, No. 4 (518-530).

[6] Indrawati, Lilik; Pattinama, Marcell Mathias. "Brand Image, Kualitas Pelayanan Dan Kepuasan Konsumen Di Dalam Pengaruhnya Terhadap Minat Ulang Penggunaan Aplikasi Dana". Jurnal Bisnis dan Manajemen. V. 8, n. 1, p. 16 - 21, April 2021.

[7] Darwis, D., Wahyuni, D., \& Dartono. (Juni 2020). "Sistem Informasi Akuntansi Pengolahan Dana Kas Kecil Menggunakan Metode Imprest Pada Pt Sinar Sosro Bandar Lampung”. Jurnal Teknologi dan Sistem Informasi (JTSI), Vol. 1, No. 1, p. 15 - 21.

[8] Paranoan, N., Tandirerung, C. J., \& Paranoan, A. (2019). "Pengaruh Pemanfaatan Teknologi Informasi Dan Kompetensi Sumber Daya Manusia Terhadap Efektivitas Sistem Informasi Akuntansi”. Jurnal Akun Nabelo, Vol 2, No 1 (2019) pp. 181-196.

[9] Tarantang, J., Awwaliyah, A., Astuti, M., \& Munawaroh, M. (Juli 2019). "Perkembangan Sistem Pembayaran Digital Pada Era Revolusi Industri 4.0 Di Indonesia”. Jurnal Al Qardh, Volume 4 (60-75). 
[10] Sihotang, J. S. (Agustus 2020). "Pengaruh Kualitas Sistem, Kualitas Layanan Dan Kualitas Informasi Terhadap Kepuasan Pengguna Sistem Aplikasi Keuangan Tingkat Instansi (SAKTI)”. Jurnal Akuntansi Bisnis \& Publik, Vol. 11 No.1 (1-9). 